\title{
Pesquisa de doutorado pela faudsp ReCEBE IMPORTANTE PRÊMIO NACIONAL
}

PRÊMIO MARTA ROSSETTI BATISTA RECONHECE PESQUISA QUE PROPÕE MÉTODO E ABORDAGEM INÉDITOS SOBRE ARQUITETURA RELIGIOSA DE OURO PRETO NO SÉCULO I8, UM DOS ACERVOS MAIS IMPORTANTES DO PAÍS

\section{Rodrigo Bastos}

\section{0 prêmio}

A entrega do prêmio aconteceu em 07 de junho de 2010, na sede do Instituto de Estudos Brasileiros da USP, Cidade Universitária, São Paulo-SP.

Em sua segunda edição, o Prêmio Marta Rossetti Batista reconhece o arquiteto e engenheiro Rodrigo Almeida Bastos por sua tese de doutorado em arquitetura, defendida na Universidade de São Paulo em março de 2009; orientação do professor Mário Henrique Simão D‘Agostino e apoio da Fapesp/Capes. Trata-se de um prêmio nacional, organizado pelo Instituto de Estudos Brasileiros da Universidade de São Paulo. A premiação reconhece, a cada dois anos, a melhor pesquisa inédita sobre arte e arquitetura escrita no Brasil. Nessa edição do prêmio, participavam trabalhos produzidos desde 2005, especialmente sobre os períodos barroco e moderno.

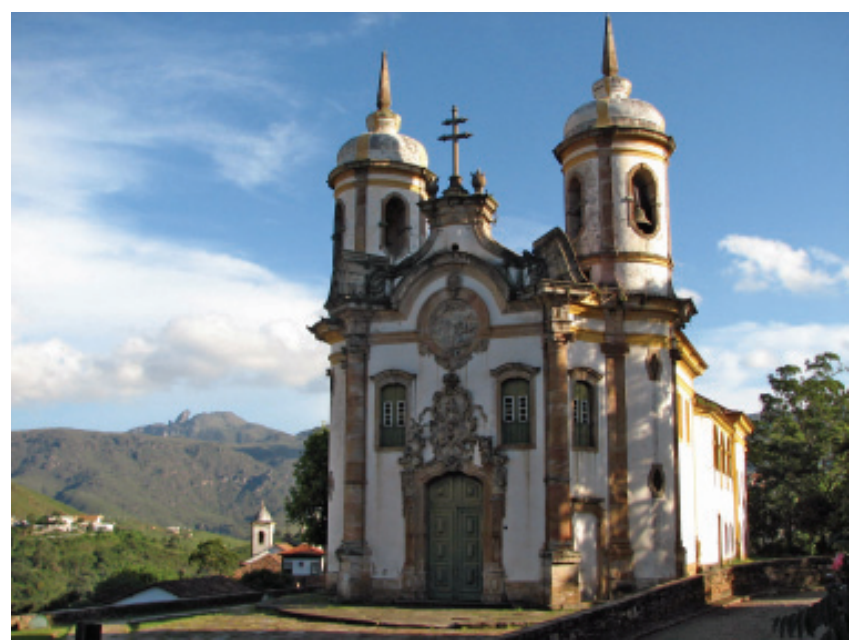

Vista da Igreja da Ordem Terceira de São Francisco de Assis, com Serra e Pico do Itacolomi ao fundo - Ouro Preto.

Frontispício da Igreja da Ordem Terceira de São Francisco de Assis Ouro Preto.

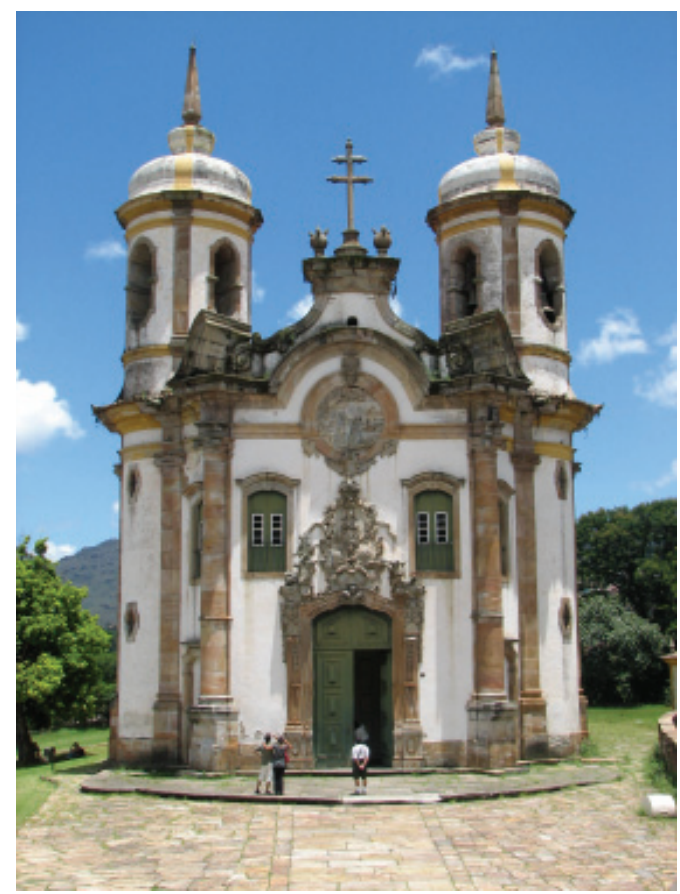

PÓS V.I 7 N.28 - SÃO PAULO DEZEMBRO 20 IO 


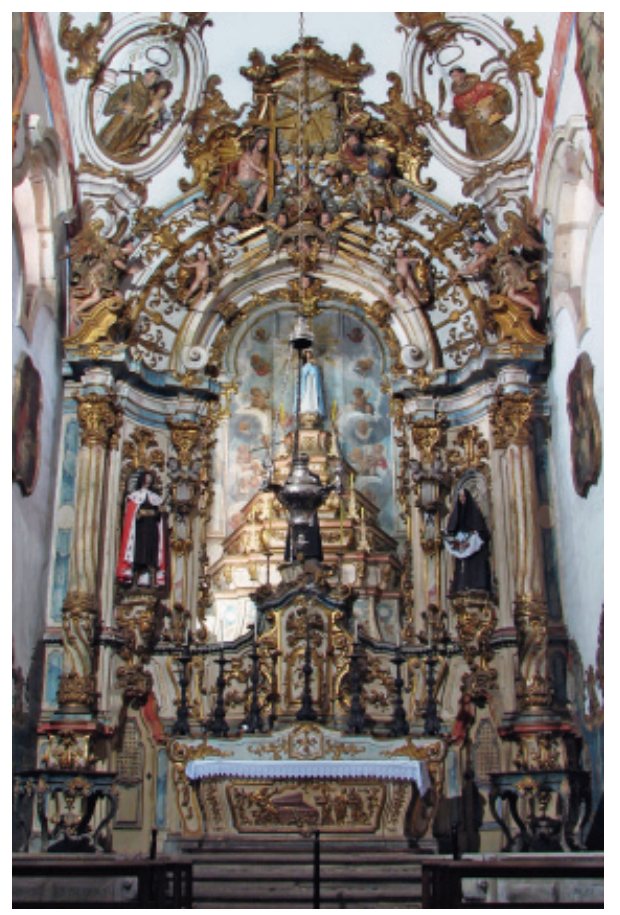

Capela e retábulo-mor da Igreja da Ordem Terceira de São Francisco de Assis - Ouro Preto

Vista da Igreja da Ordem Terceira da São Francisco de Assis - Ouro Preto

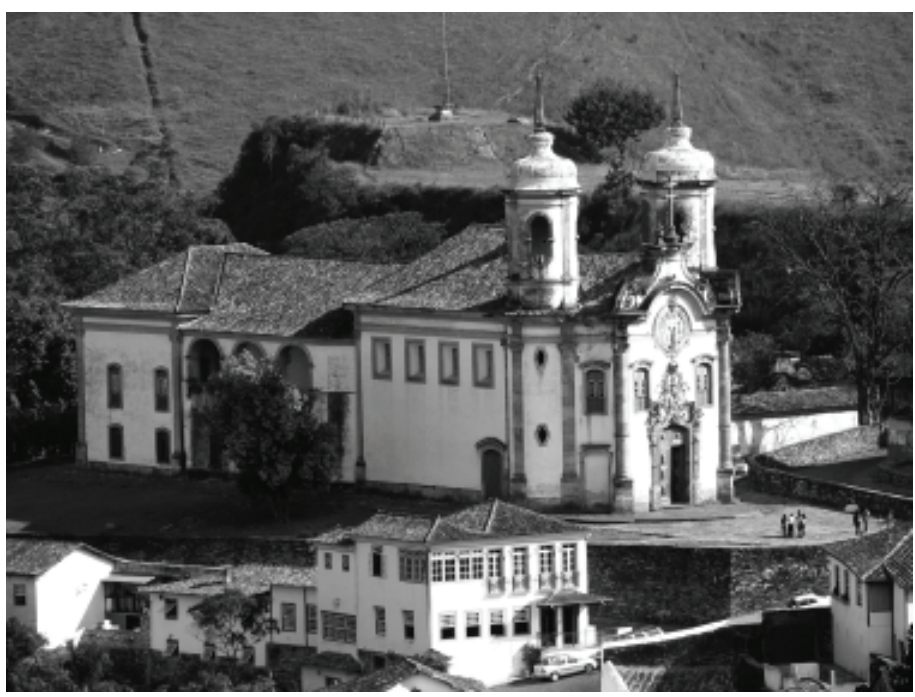

pós-

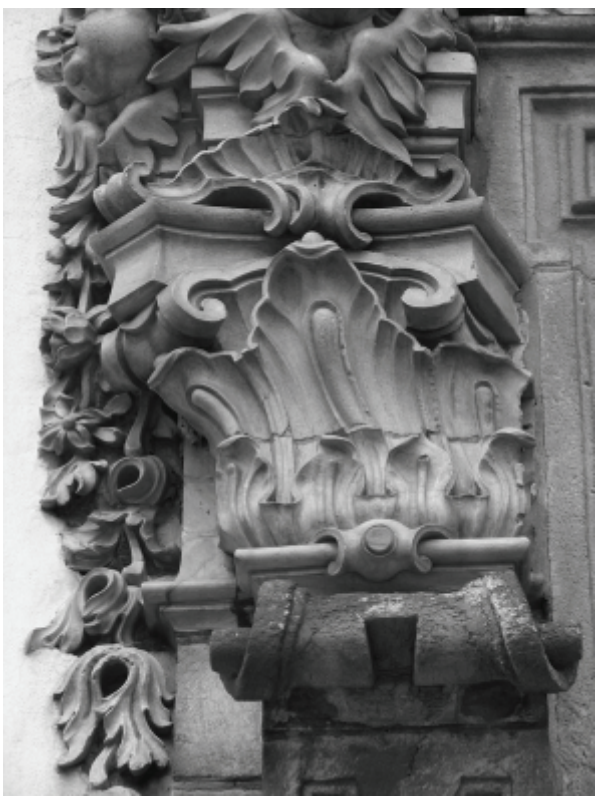

Detalhe do capitel da Portada da Igreja da Ordem Terceira de São Francisco de Assis - Ouro Preto

Detalhes do frontispício da Igreja da Ordem Terceira de Nossa Senhora do Carmo - Ouro Preto

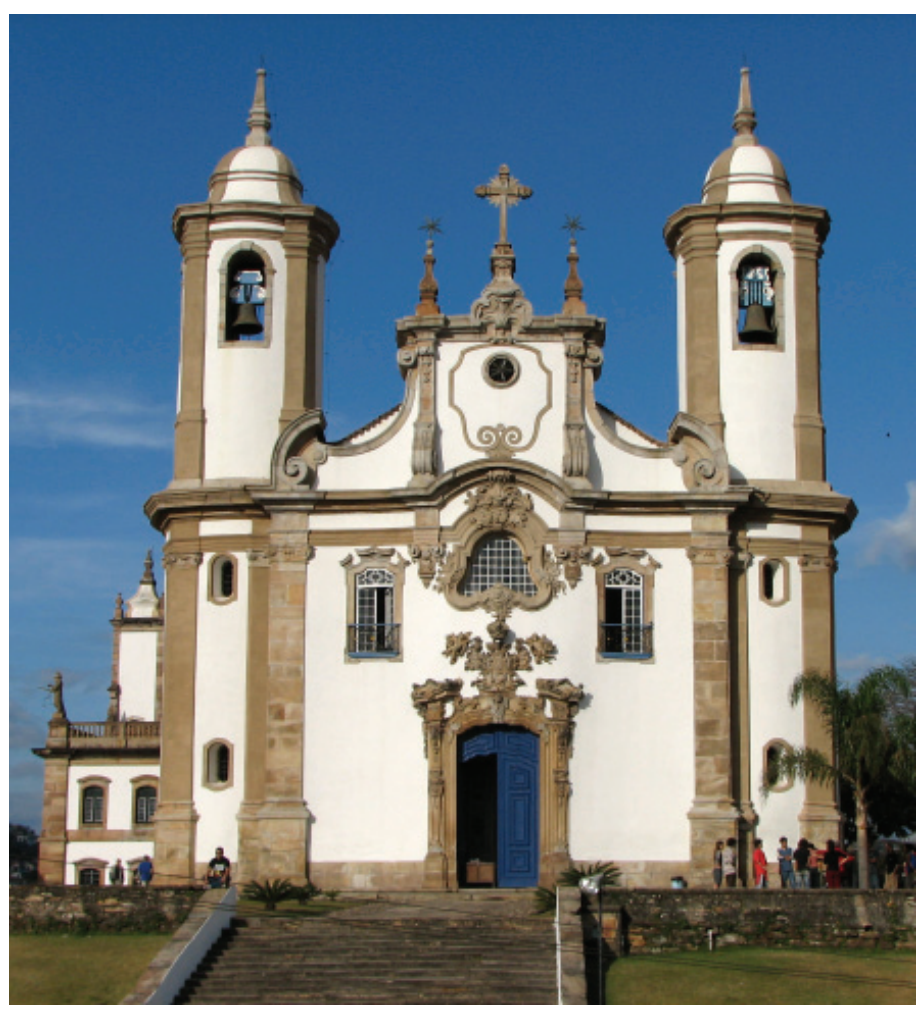


Portada da Igreja da Ordem Terceira de Nossa Senhora do Carmo Ouro Preto

Capela e retábulo-moor da Igreja da Ordem Terceira de Nossa Senhora do Carmo Ouro Preto

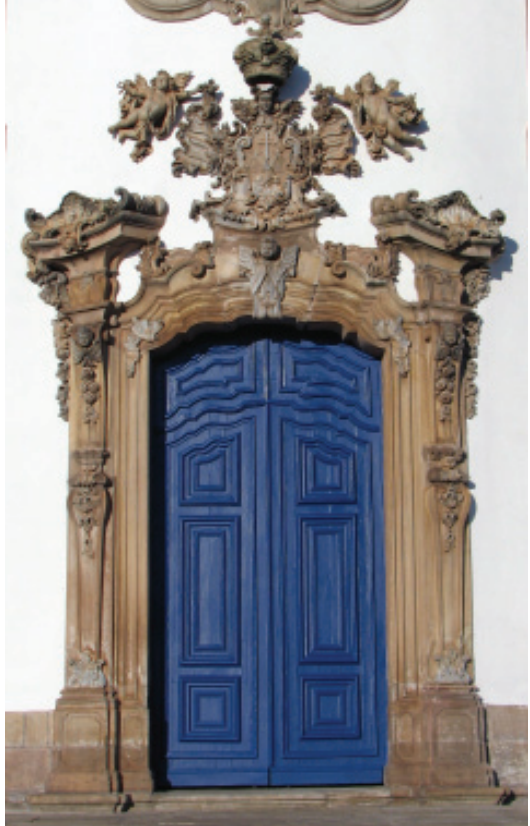

Portada da Igreja da Ordem Terceira de Nossa Senhora do Carmo - Ouro Preto

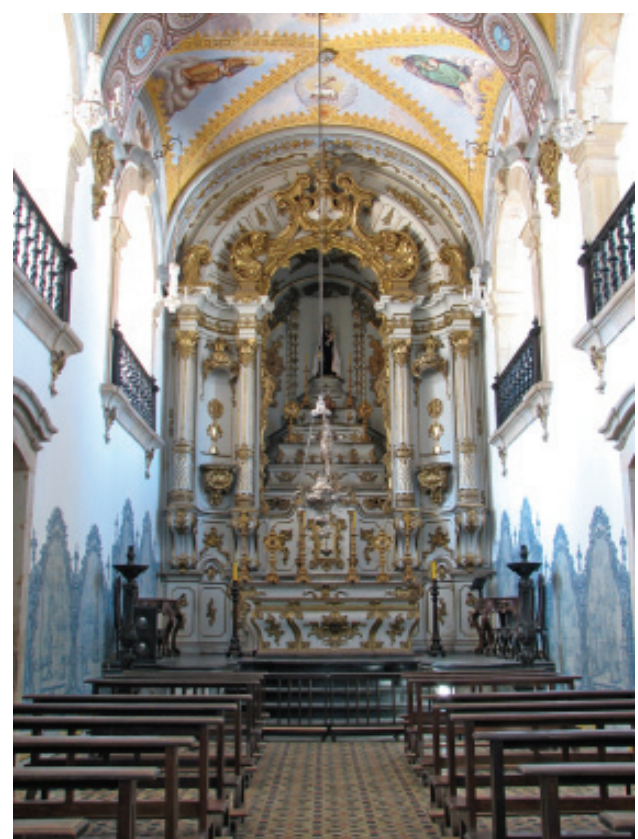

Capela e retábulo-moor da Igreja da Ordem Terceira de Nossa Senhora do Carmo - Ouro Preto

A pesquisa de Rodrigo, intitulada A maravilhosa fábrica de virtudes: O decoro na arquitetura religiosa de Vila Rica, Minas Gerais (1711-1822), tem o mérito de renovar significativamente a compreensão e o método de análise da arquitetura do século 18, e representa uma importante contribuição à história da arquitetura e do patrimônio arquitetônico e artístico de Minas Gerais, um dos acervos mais importantes do país. De forma inédita na historiografia, a arquitetura de Minas Gerais no século 18 é analisada por meio da reconstituição histórica dos preceitos e doutrinas que orientavam, naquele tempo, a invenção e a fábrica da arquitetura. Foram estudados templos como a Igreja Matriz de Nossa Senhora do Pilar e as igrejas das ordens terceiras de São Francisco de Assis e Nossa Senhora do Carmo, alguns dos exemplares mais paradigmáticos da arquitetura colonial não apenas em Minas Gerais, mas em todo Brasil.

O estudioso já havia recebido prêmio nacional por suas pesquisas em 2007, o 8o Prêmio Jovens Arquitetos, com um texto em que demonstrava, ao contrário do que se pensava até então, que as povoações históricas de Minas Gerais, como Ouro Preto, Sabará e Mariana, não se desenvolveram espontaneamente. "Elas evidenciam a observação de preceitos de ordem, adequação e decoro relativos a seu tempo", afirma o pesquisador; e continua: "O conhecimento e as práticas daquele tempo se perderam nos séculos XIX e XX, restando à nossa história reconstituí-los." O texto - Regularidade e ordem das povoações mineiras no século XVIII - foi apresentado no IX Seminário História da Cidade e do Urbanismo, na FAUUSP, 2006, e publicado na Revista do IEB, n. 44, em 2007. O pesquisador se dedica a tais estudos desde 2001. O novo prêmio vem ratificar o caminho e as contribuições científicas relevantes para a pesquisa da arquitetura e do urbanismo luso-brasileiros. 


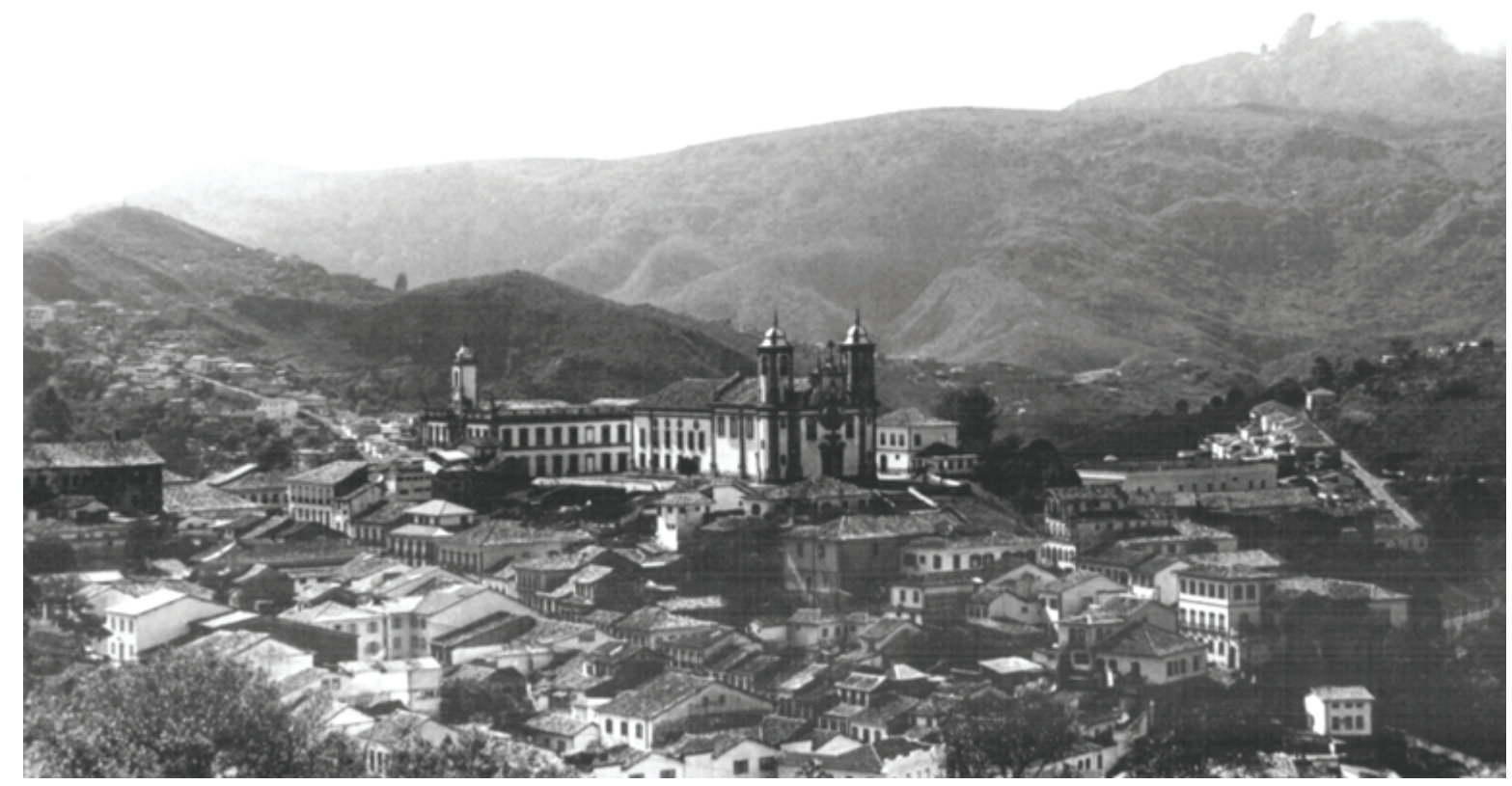

Vista de Ouro Preto, Arraial de Nossa Senhora do Pilar - Ouro Preto

\section{Pesquisa Inédita}

A tese premiada: A maravilhosa fábrica de virtudes: O decoro na arquitetura religiosa de Vila Rica, Minas Gerais (1711-1822) procura reconstituir a história e os sentidos de alguns dos exemplares mais paradigmáticos da arquitetura religiosa de Ouro Preto, ao mesmo tempo em que faz também, de forma inédita na historiografia da arquitetura no Brasil, uma reconstituição histórica de preceitos e doutrinas artísticas que fundamentavam as práticas artísticas e arquitetônicas daquele tempo. Além da renovação metodológica e de muitos documentos


primários inéditos levantados, a tese reconstitui, historicamente, dezenas de termos, doutrinas e preceitos como o decoro (preceito central das artes daquele tempo), o engenho, a elegância, o asseio, a formosura, a maravilha, a perfeição. Esses conceitos, recuperados pela pesquisa, perderam a operacionalidade nos séculos 19 e 20, e tiveram, assim, seus sentidos esquecidos ou transformados pela mentalidade romântica e moderna.

\section{Obs.:}

A tese de Rodrigo Bastos, no dia 3 de dezembro de 2010 recebeu menção na premiação do I Enanparq - Primeiro Encontro da Associação Nacional de Pesquisa e Pós-Graduação em Arquitetura e Urbanismo, realizado no Rio de Janeiro.

Rodrigo Bastos, no recebimento do

Prêmio. Instituto de Estudos brasileiros

da USP, 07 de junho de 2010 


\section{Rodrigo Bastos}

Engenheiro civil pela Universidade Federal de Goiás, arquiteto urbanista pela Puc-Goiás, mestre em Arquitetura e Urbanismo pela Universidade Federal de Minas Gerais e doutor em Arquitetura pela Universidade de São Paulo (orientação do Prof. Dr. Mário Henrique Simão D“Agostino), com doutorado "sanduíche" pelo Departamento de História da Arte da Universidade Nova de Lisboa (orientação do Prof. Dr. Rafael Moreira).

É, atualmente, professor adjunto do Departamento de Análise Crítica e Histórica da Arquitetura e do Urbanismo da Escola de Arquitetura da UFMG, do curso de especialização lato sensu em Cultura e Arte Barroca, do Instituto de Filosofia, Artes e Cultura da Universidade Federal de Ouro Preto e do curso de especialização lato sensu em Revitalização Urbanística e Arquitetônica da UFMG. Em 2007, recebeu prêmio pelo melhor ensaio crítico de Arquitetura e Urbanismo, 8o Prêmio Jovens Arquitetos, com o texto Regularidade e ordem das povoações mineiras no século XVIII.

Rua Itambé, n. 35, ap. 403. Floresta

30150-150 - Belo Horizonte, MG

rodrigobastos.arq@gmail.com

(31) 3224-4024; (31) 9651-4363 